\title{
A GEOGRAFIA DO PETRÓLEO EM TRANSIÇÃO: CONSIDERAÇÕES A PARTIR DAS DESCOBERTAS DE FONTES NÃO CONVENCIONAIS DE PETRÓLEO NA AMÉRICA
}

\author{
GEOGRAPHY OF OIL IN TRANSITION: CONSIDERATIONS FROM THE \\ DISCOVERIES OF OIL UNCONVENTIONAL SOURCES IN AMERICA
}

\author{
Ciro Marques Reis \\ Doutorando do Programa de Pós-Graduação em Geografia da UERJ \\ ciro.reis@gmail.com
}

Mônica Sampaio Machado

Professora do Departamento de Geografia da UERJ Bolsista Produtividade em Pesquisa CNPq-2 monica.sampaio@pq.cnpq.br

\begin{abstract}
RESUMO
Este artigo apresenta considerações sobre a nova geopolítica do petróleoa partir das recentes descobertas de enormes jazidas de petróleo de fontes não convencionais em regiões fora do eixo Oriente Médio-Norte da África, especificamente, o xisto nos EUA, as areias betuminosas no Canadá e o pré-sal no Brasil. Busca-se, assim, delinearalguns cenários geopolíticos possíveis considerando a entrada dessasnovas fontes de petróleo no comércio mundial.Para tanto, este artigo foi organizado emtrês partes. Inicialmente, um breve balanço sobre o estado da arte dos atuais estudos sobre a geopolítica do petróleo no Brasil será apresentado. Em seguida, será expostoum quadro sobre a distribuição geográfica da indústria do petróleo no mundo,as principais reservas provadas, os países e regiões produtoras e consumidoras mais importantes e as principais atividades de refino, com destaque para o papel das grandes companhias.Por fim, são apresentadasas possibilidades de reestruturação e reordenamento geográfico e geopolítico do petróleo no mundo,considerando essas novas fontes energéticas não convencionaisdos EUA, Canadá e Brasil.
\end{abstract}

Palavras-chave: Geopolítica, Petróleo, Fontes não convencionais, Geografia.

\footnotetext{
ABSTRACT

This article presents some comments regarding the novel geopolitics of oil due to the recent discovery of huge oil deposits of unconventional sources in regions outside of the shaft Middle East-North Africa, specifically in the U.S. shale, tar sands in Canada and pre-salt in Brazil. This study aims outlining some possible geopolitical scenarios taking into consideration the ingress of these new sources of oil in the world trade. In order to do so, this article is organized into three parts.Initially a brief assessment on the state of the art of current studies on the geopolitics of oil in Brazil will be presented. Then, will be exposed the geographical distribution of the oil industry in the world, the main

Geo UERJ. Rio de Janeiro - Ano 16, no. 25, v.2, $2^{\circ}$ semestre de 2014, pp.419-457

ISSN: 1415-7543 E-ISSN: 1981-9021

http://www.e-publicacoes.uerj.br/index.php/geouerj
} 
proven reserves, the most important producing and consuming countries and regions, and major refining activities, with emphasis on the role of large companies. Finally, the possibilities of geographical restructuring and geopolitical reordering of oil in the world are presented, considering these new unconventional energy sources in the US, Canada and Brazil.

Key-words: Geopolitcs, Oil, Unconventional sources, Geography.

\section{Introdução}

Asanálises geográfica e geopolítica do petróleo sempre estiveramligadas e influenciadas de forma decisiva,pelo ambiente político e econômicodo Oriente Médio,do norte da África, e dos países membros da OPEP (Organização dos Países Exportadores de Petróleo).A histórica centralidade destas regiões e da OPEPnas questões ligadas ao petróleo é inegável (YERGIN, 2012). Aanálise das redes globais do setor petrolífero permite reconhecer um cenário que apresenta de um lado,países e regiões produtoras, e do outro, países e regiões consumidoras. No entanto, impulsionados por avanços técnicos que possibilitam a exploração e produção de petróleo de fontes não convencionais, novos atores começam a desenhar uma nova geografia do petróleo no mundo.

As areias betuminosas do Canadá, o gás e o óleo de xisto norte-americano, o pré-sal brasileiro, em conjunto com asjá conhecidas reservas de óleo extra pesado da Venezuela, apontam para um possível deslocamento ou descentralização do eixo geográfico e geopolítico do petróleo, de regiões tradicionais como Oriente Médio e África setentrional para as Américas.Assim, essasrecentes descobertas de grandes reservas de fontes não convencionais nos EUA, Canadá e Brasil, e a expectativa do aumento de produção da commoditynestes países, parecem indicar o surgimento de uma nova configuração dageografia do petróleo no mundo, com o surgimento de um eixo pan-americano do setor petrolífero.

O objetivo deste trabalho é apresentar a atual configuração econômico espacial do petróleo no mundo e chamar a atenção para uma nova composição geopolítica em formação, com a descoberta e exploração do potencial energético pan-americano. Não é demais assinalar que essa nova composição em desenvolvimento se deve à centralidade do petróleo no mundo contemporâneo. Mesmo com o crescimento dos usos das fontes alternativas de energia, o petróleo é a matriz energética fundamental da economia e 
sociedade na atualidade, eprovavelmente continuará sendo pelo menos nos próximos 40. Assim, seu controle, exploração e distribuição representam fator de destaque na geopolítica mundial e não se pode negar que grande parte dos conflitos internacionais tem origem no petróleo e seus derivados. Em tempos de globalização, portanto,ocontrole, exploração e distribuição desse recurso natural é condição fundamental para o enriquecimento e competitividade das nações e dos blocos regionais. Assim, esse novo cenário energético americano que parece se configurar, além de possibilitar uma alteração na geopolítica mundial, apresenta uma oportunidade, principalmente ao Brasil, de potencializar sua força e atuação no cenário político e econômicointernacional.

Pensar a participação pan-americana, e especificamente, a brasileira, na geopolítica mundial tendo em consideração essas novas e grandes jazidas de petróleo de fontes não convencionais, constitui objetivo último deste trabalho. Assim, antes de apresentar a atual configuração do petróleo no mundo e as novas possibilidades geopolíticas frente às reservas mencionadas, algumas observações sobre a abordagem politica nos estudos geográficos e, especificamente, sobre a geopolítica do petróleo no Brasil merecem atenção.

\section{Os estudos geopolíticos do petróleo no Brasil}

Contemporaneamente, vários autores têm assinalado que a perspectiva política deveria ser o eixo de investigação geográfica e do seu campo científico. Yves Lacoste (1977 e 2003), Claude Raffestin (1980) e Bertha Becker (1988), são alguns exemplos dessa posição. De forma diferenciada, esses intelectuais defenderam oconhecimento geográfico como estratégico, não se limitando aos estados nacionais. Renovaram a Geografia Política e resgataram a geopolítica, que até finais da década de 1970 era reconhecida como atividade orquestrada por governos reacionários, tiranos e largamente utilizada pela propaganda nazista. Associada ao conteúdo ideológico nazista e aos seus instrumentos expansionistas, ou seja, às táticas militares, às estratégias e à logística do estado nacional alemão, a geopolítica desapareceu do meio acadêmico mundial ficando restrita, do final da Segunda Guerra Mundial à década de 70, aos aparelhos de Estado, às Forças Armadas (MYAMOTO,1981; VESENTINI, 2000; COSTA, 2008). Os autores 
mencionados esforçaram-se na reabilitação do termo desenvolvendo e atualizando um suporte teórico e conceitual em que outras escalas de poder, além da nacional, passassem a ser valorizadas, assim como seus suportes materiais e suas ações de controle, ou seja,os territórios e as territorialidades.

Essas alterações, na realidade, estavam de acordo com o novo ordenamento e nova lógica de organização sócio-espacial planetária, fruto da aceleração da internacionalização da economia e dos mercados, evidenciada na década de 1970. Esse processo foi denominado por Milton Santos (1988 e 1997) comomundialização ou globalização, mais amplo e complexo do que ainternacionalização, representando um sentido mais elaborado e expressivo das relações econômicas, sociais e políticas, em que o mais notável é a possibilidade de tudo conhecer e utilizar em escala planetária. Se, por um lado, a globalização possibilitou e integrou, através de suas redes técnicas, mercados e lugares em escala jamais alcançada, por outro, provoca grandes fragmentações e desigualdades territoriais que ultrapassam as discussões limitadas ao estado nacional. Como hoje o estado nacional não é o único marco jurídico-político territorial que estabelece e intermedeia a relação dos indivíduos e instituições com o mundo, a noção de estado territorial evolui para a transnacionalização do território.As mudanças postas por esse processo criaram, ainda, simultaneamente, vários territórios descontínuos e fragmentados, promovendo uma intensa restruturação do espaço mundial em diferentes escalas geográficas, na qual territórios se fundem enquanto outros se desintegram.

Nesse sentido, na atualidade, pensar geopoliticamente significa incorporar atores, instituições e escalas territoriais diversas, que no trabalho em tela envolve dimensões além das fronteiras físicas nacionais, ou seja, implica no continente América e o Brasil nesse contexto. Como o petróleo é um recurso natural de extraordinário valor estratégicopara países e regiões que os controlam e,provavelmente,continuarásendo pelo menos nas próximas décadas, apesar da crise ambiental e da pressão mundial por energias limpas, sua cadeia produtiva é complexa edegrande alcance e impacto territorial. Em função dessa extensão e complexidade, sua investigação tem sido levada à frente de forma incisiva por vários campos científicos, tanto nas ciências humanas quando nas ciências naturais. Entretanto, embora estudos sobre petróleo se ampliem no 
Brasil, os trabalhos relacionados à geopolítica ainda não são muito numerosos, tanto na Geografia quanto nas ciências humanas.

No campo científico geográficosão comuns, no estudo do petróleo, temáticascomo:reestruturação econômico espacial de municípios em áreas de influência do pré-sal, desenvolvimento regional advindo da economia do petróleo, divisão e gestão dos royalties do petróleo, impactos sociais e ambientais de sua exploração e papel desempenhado pela Petrobras no reordenamento territorial. Apenas recentemente estudos geopolíticos sobre o petróleo, principalmente na escala global, vêm tomando expressão, embora não seja nova a preocupação da Geografia com esse recurso natural. Podem ser observados, por exemplo, na Revista Brasileira de Geografia, publicação do Instituto Brasileiro de Geografia e Estatística (IBGE) que veiculoutrabalhos geográficos desenvolvidos no Brasil entre 1939 e 1996, os estudos pioneiros de autoria de Sylvio Fróes de Abreu nas décadas de 30 e 40. Apesar de serem trabalhos de reconhecimento territorial, principalmente topográfico, fisiográfico e geológico, esses artigos apresentavam grande preocupação com a ausência desse recurso natural no desenvolvimento nacional e com seu impacto político e espacial, principalmentenas cidades e regiões de suas descobertas.

O recente livro organizado pelos geógrafosFrédéric Monié e Jacob Binsztok(2012), Geografia e Geopolítica do Petróleo,reúne estudos atuais sobre o petróleo a partir da análise econômica e geopolítica. Exemplo do tratamento geopolítico do petróleo pela Geografia, contudo, essa publicação não se limitaàs abordagens dessa área de conhecimento. Apresenta também trabalhos de pesquisadores de outras áreas como a Engenharia, Economia e Oceanografia. É interessante observar que em função da importância, alcance e impacto desse recurso natural na atualidade, sua investigação tem exigido um tratamento cada vez mais interdisciplinar, é o que podemos observar na publicação mencionada. Aqui são apresentadas considerações interessantes sobre a segurança energética e a interdependência entre as nações, e, especificamente sobre as opções brasileiras com relação à exploração, gestão e comercialização do petróleo e das fontes energéticas alternativas. Podem também ser encontrados quatro grandes eixos aglutinadores: atores, redes e regulações do petróleo; petróleo e desenvolvimento; o novo mapa mundial do petróleo e, por fim, a indústria petrolífera no estado do Rio de Janeiro. 
Nas ciências humanas,as investigações sobre petróleo têm sido mais expressivas na Economia e no Direito. Na Economia,destacam-se os estudos vinculados aos desenvolvimentos regionais pela indústria de energia, com preocupações ambientais. No Direito predominam os aspectos jurídicos da exploração dos recursos naturais estratégicos e a regulação desses setores na esfera nacional e internacional. Entretanto, a produção bibliográfica sobre a geopolítica do petróleo no contexto das novas descobertas do pré-sal encontra-se ainda bastante incipiente, possivelmenteem função dessas descobertas terem sido anunciadas muito recentemente, novembro 2007.

Dentre os livros publicados sobre o pré-sal valem menção: Pré-sal: história, doutrina e comentário às leis, de Claudio Pinho (2010), Mar de Riqueza, Terras de Contrastes, de Rosélia Piquet (2011) eBrasil, novas oportunidades, organizado por João Paulo dos Reis Velloso (2010). É interessante observar que a maior concentração de trabalhos encontra-se nos blogs e sites, dentre os quais cabem destacar o da Agência Nacional do Petróleo, Gás Natural e Biocombustíveis (ANP) (http://www.anp.gov.br), que apresenta dados sobre legislação, anuários estatísticos, relatórios institucionais, boletins, livros e revistas ligadas ao setor de petróleo no Brasil; o do Centro de Informações da Produção de Petróleo e Gás (CIPEG) do Departamento de Recursos Minerais do Estado do Rio de Janeiro (http://www.petroleo.rj.gov.br/site/index.php), e o site da Consultoria Legislativa (http://www2.camara.gov.br/acamara/estruturaadm/conle), que disponibiliza publicações como estudos e notas técnicas, livros eletrônicos e teses em 21 áreas temáticas como Meio Ambiente e Direito Ambiental, Organização Territorial, Desenvolvimento Urbano e Regional, Trânsito e Transportes, e Recursos Minerais, Hídricos e Energéticos Recursos minerais, hídricos e energéticos.

Significativa contribuição sobre geopolítica e o pré-sal brasileiro vem sendo dada pelo Itamaraty, através da Fundação Alexandre Gusmão, Ministério das Relações Exteriores. Valem destaques os trabalhos de Luiz Alberto Moniz Bandeira,Geopolítica e Política Exterior Estados Unidos, Brasil e América do Sul (2009); de Neil Giovanni Paiva Benevides,Relações Brasil-Estados Unidos no setor de energia(2011); de Fernando Pimentel, O fim da era do petróleo e a mudança do paradigma energético mundial: perspectivas e desafios para a atuação diplomática brasileira(2011); de José Vicente de Sá Pimentel, O Brasil os BRICS e a agenda internacional (2012) e José 
Vicente de Sá Pimentel (et. al.), A América do Sul e a integração regional Rio de Janeiro (2012).

Como pode ser constatado, em virtude do novo e potencial quadro energético americano, com a incorporação das recentes descobertas das fontes não convencionais de petróleo dos EUA, Canadá e Brasil, ainda não houve tempo para a realização de um número expressivo de estudos analíticos e prospectivos sobre o seu papel no cenário energético mundial. O mesmo pode ser afirmado com relação ao pré-sal brasileiro e ao Brasil, embora já se observe um incremento de estudos e grupos de pesquisa sobre a temática.

Buscando dar uma contribuição ao debate, este trabalho irá agora apresentar dados e informações sobre o petróleo no mundo. Primeiramente, será exposta a atual distribuição geográfica do petróleo, observando o mapa das reservas provadas mundiais, da produção e do consumo, por países e regiões. Serão também mencionadas as principais atividades de refino, com destaque para o papel das grandes companhias. Em seguida, a partir das emergentes fontes não convencionais de petróleo dos EUA, Canadá e Brasil, serão apresentadas considerações sobre a atuação e participação desses países no mercado mundial do petróleo. Aqui são comentados tanto seus avanços técnicos e desafios internos de ordem estrutural, quanto suas novas possibilidades de atuação na geopolítica do petróleo no mundo.

\section{A atual distribuição geográfica do petróleo no mundo.}

Reservas e produção.

O petróleo e o gás, ao lado do carvão mineral, sãoos recursos energéticos,em uso efetivo,mais importantes do planeta, e possuem peso significativo na composição da matriz energética mundial.Nesta, a porcentagem de participação do petróleo e gás tem se mantido praticamente estável nos últimos 40 anos, correspondendo, em média,a aproximadamente $58 \%$ do suprimento de energia primária totalutilizadano mundo (IEA, 2012).

As reservas provadas mundiaisde petróleo bruto estão na casa de 1,48 trilhões de barris.Aproximadamente $81 \%$ dessas reservas pertencem aos territórios dos países membros da OPEP, que abarca, alémdas grandes potências petrolíferasdo Oriente 
Médio: Irã, Iraque, Kuwait, Arábia Saudita, Catar, Emirados Árabes, também países do norte da África: Líbia e Argélia,da África subsaariana: Nigéria e Angola, e países sulamericanos: o Equador e a Venezuela.Esta última, sozinha, possui aproximadamente 297 bilhões em reservas, ocupando a primeira colocação em se tratando especificamente de reservas de petróleo, apenas rivalizada pela Arábia Saudita com 265 bilhões de reservas provadas (OPEP, 2012).

Tabela 1 - Maiores reservas provadas petróleo (bilhões de barris, crudeoil) por país e regiões-2013

\begin{tabular}{|c|c|c|c|c|c|}
\hline Países & Barris & $\begin{array}{c}\text { Membro } \\
\text { OPEC }\end{array}$ & Região & Barris & $(\%)$ \\
\hline Venezuela & 298,350 & $\mathrm{Sim}$ & Total Mundial & $1,489,865$ & 100,0 \\
\hline Arábia Saudita & 265,789 & Sim & Oriente Médio & 803,182 & 53,9 \\
\hline Irã & 157,800 & Sim & $\begin{array}{l}\text { América } \\
\text { Latina }\end{array}$ & 338,289 & 22,7 \\
\hline Iraque & 144,211 & Sim & $\begin{array}{l}\text { Europa e } \\
\text { Eurásia }\end{array}$ & 132,044 & 8,8 \\
\hline Kuwait & 101,500 & Sim & África & 128,149 & 8,6 \\
\hline $\begin{array}{l}\text { Emirados Árabes } \\
\text { Unidos }\end{array}$ & 97,800 & Sim & $\begin{array}{l}\text { Leste Europeu } \\
\text { e Eurásia }\end{array}$ & 119,877 & 8,0 \\
\hline Rússia & 80,000 & & $\begin{array}{l}\text { Ásia e } \\
\text { Pacífico }\end{array}$ & 50,208 & 3,3 \\
\hline Líbia & 48,363 & Sim & $\begin{array}{l}\text { América } \\
\text { Latina Sem } \\
\text { Venezuela }\end{array}$ & 39,939 & 2,7 \\
\hline Nigéria & 37,070 & Sim & $\begin{array}{l}\text { América do } \\
\text { Norte }\end{array}$ & 37,893 & 2,5 \\
\hline Estados Unidos & 33,000 & & $\begin{array}{l}\text { Oeste } \\
\text { Europeu }\end{array}$ & 12,267 & 0,8 \\
\hline Cazaquistão & 30,000 & & & & \\
\hline Catar & 25,244 & Sim & & & \\
\hline China & 24,428 & & & & \\
\hline
\end{tabular}

Geo UERJ. Rio de Janeiro - Ano 16, no. 25, v.2, $2^{\circ}$ semestre de 2014, pp.419-457

ISSN: 1415-7543 E-ISSN: 1981-9021

http://www.e-publicacoes.uerj.br/index.php/geouerj 


\begin{tabular}{lcc|c}
\hline Brasil & 13,219 & & \\
Argélia & 12,200 & Sim & \\
México & 10,070 & & \\
Angola & 9,011 & Sim & \\
\hline
\end{tabular}

Fonte: OPEC - Annual Statistical Bulletin 2014.

Elaboração: GeoBrasil, Grupo de Pesquisa Geográfica Brasileira: História e Política (UERJ)

Observação: O Canada não consta na lista em virtude não terem sido computados os óleos considerados não convencionais, como aqueles extraídos das areias betuminosas daquele país. O Canada ocuparia a terceira posição com 175 bilhões de barris de reservas.

A observação dos dados supracitados na Tabela 1 evidencia o protagonismo do Oriente Médio, detentor de mais da metade das reservas provadas mundiais, em relação às outras regiões do planeta.Pode-se percebero peso da Venezuela na composição das reservas da América Latina (88,2\% das reservas da região), ea dependência da Europa, América do Norte, eÁsia,do petróleo existente em reservas estrangeiras. Vale ressaltar uma significativa presença da Rússia, salientada em trabalhos recentes (BROS\&RICHARD, 2011; MAUGERI, 2012; RAFAEL, 2012), como país de peso na geopolítica energética mundial, seja isoladamente, ou através de alianças regionais com ex-repúblicas soviéticas, em especial o Cazaquistão. Porém, as regiões tradicionais, além de possuírem as maiores reservas, também permanecem como maiores produtoras de petróleo. Percebe-se na Tabela 2, que mesmo com a presença de Rússia, EUA, e China ocupando 3 das 4 primeiras colocações no ranking dos maiores produtores de petróleo, a análise por região ainda evidencia o Oriente Médio como a maior centro produtor de petróleo no mundo.

Tabela 2 - Maiores produtores de petróleo (milhões de barris p/ dia, crudeoil) por país e regiões -2013

\begin{tabular}{ccc|ccc}
\hline País & Barris & $\begin{array}{c}\text { Membro } \\
\text { OPEC }\end{array}$ & Região & Barris & (\%) \\
\hline Rússia & $10,146.6$ & & Total & $72,842.2$ & 100,0 \\
\hline
\end{tabular}

Geo UERJ. Rio de Janeiro - Ano 16, nº. 25, v.2, $2^{\circ}$ semestre de 2014, pp.419-457

ISSN: 1415-7543 E-ISSN: 1981-9021

http://www.e-publicacoes.uerj.br/index.php/geouerj 


\begin{tabular}{|c|c|c|c|c|c|}
\hline & & & Mundial & & \\
\hline Arábia Saudita & $9,637.0$ & Sim & $\begin{array}{l}\text { Oriente } \\
\text { Médio }\end{array}$ & $23,834.5$ & 32,7 \\
\hline Estados Unidos & $7,441.2$ & & $\begin{array}{l}\text { Leste } \\
\text { Europeu e } \\
\text { Eurásia }\end{array}$ & $12,757.3$ & 17,5 \\
\hline China & $4,164.1$ & & $\begin{array}{l}\text { América } \\
\text { Latina }\end{array}$ & $9,680.2$ & 13,3 \\
\hline Irã & $3,575.0$ & Sim & $\begin{array}{l}\text { América do } \\
\text { Norte }\end{array}$ & $8,822.1$ & 12,1 \\
\hline Iraque & $2,979.6$ & Sim & África & $7,640.1$ & 10,5 \\
\hline Kuwait & $2,924.7$ & Sim & $\begin{array}{l}\text { Ásia e } \\
\text { Pacífico }\end{array}$ & $7,386.4$ & 10,1 \\
\hline $\begin{array}{l}\text { Emirados Árabes } \\
\text { Unidos }\end{array}$ & $2,796.5$ & Sim & $\begin{array}{l}\text { Oeste } \\
\text { Europeu }\end{array}$ & $2,721.6$ & 3,7 \\
\hline Venezuela & $2,789.5$ & Sim & $\begin{array}{l}\text { Leste } \\
\text { Europeu e } \\
\text { Eurásia sem } \\
\text { a Rússia }\end{array}$ & $2,610.7$ & 3,6 \\
\hline México & $2,522.2$ & & & & \\
\hline Brasil & $2,023.9$ & & & & \\
\hline Nigéria & $1,753.7$ & Sim & & & \\
\hline
\end{tabular}

Fonte: OPEC - Annual Statistical Bulletin 2014.

Elaboração: GeoBrasil, Grupo de Pesquisa Geográfica Brasileira: História e Política (UERJ)

Tambémsoberano neste quesito, o Oriente Médio responde por 32,7\% da produção mundial de petróleo na atualidade. Porém a geografia das grandes reservas não é diretamente proporcionalà geografia dos grandes produtores. Rússia, EUA, China, México e Brasil estão entre os 11 maiores produtores globais. A Venezuela, apesar de suas imensas reservas, não mantém a mesma correlação entre país possuidor de grandes reservas e grande produtor de petróleo, como é caso da Arábia Saudita, que ao lado da 
Rússia,lidera o ranking de produtores. Isso se deve, entre outros fatores, às características das reservas provadas de cada país (se com petróleo de fácil ou difícil extração), às características do óleo extraído (se de fácil ou difícil refino), e ao clima de investimentos no país, voltados para a cadeia produtiva do petróleo e gás que poderiam proporcionar avanços técnicos que permitiriam a reduçãodos custos de produção. Essas diferenças respondem, em parte, ao distanciamento de Rússia e Arábia Saudita em relação à "baixa" capacidade produtiva da Venezuela. As dificuldades em desenvolver os projetos de exploração e produção no cinturão de petróleo do Orinoco são um retrato da dificuldade venezuelana em equiparar sua capacidade produtiva com sua potencialidade petrolífera (PARRAGA, 2012).

Uma análise comparativa, em Tabela 3, sugere que na produção, o peso dos países mais industrializados e avançados tecnologicamente, já modifica o grau de participação das regiões na indústria mundial de petróleo.

Tabela 3 - Variação percentual da participação - Reservas x Produção (crudeoil) por região- 2013

\begin{tabular}{lcccc}
\hline \multicolumn{1}{c}{ Região } & $\begin{array}{c}\text { Reservas } \\
\text { Barris } \\
\text { (bilhões) }\end{array}$ & $\begin{array}{c}\text { Barris } \\
\text { produzidos } \\
\text { (milhões p/ } \\
\text { dia) }\end{array}$ & $\begin{array}{c}\text { Variação de } \\
\text { participação } \\
(\%)\end{array}$ & $\begin{array}{c}\text { Principal } \\
\text { Motor }\end{array}$ \\
\hline Total Mundial & $1,489,865$ & $72,842.2$ & 100 para 100 & - \\
Oriente Médio & 803,182 & $23,834.5$ & 53,9 para 32,7 & Arábia \\
& & & & Saudita \\
Leste Europeu & 119,877 & $12,757.3$ & 8,0 para 17,5 & Rússia \\
Eurásia & & & & \\
América Latina & 338,289 & $9,680.2$ & 22,7 para 13,3 & Venezuela \\
Ásia e Pacífico & 50,208 & $7,386.4$ & 3,3 para 10,5 & China \\
África & 128,149 & $7,640.1$ & 8,6 para 10,1 & Nigéria \\
América do Norte & 37,893 & $8,822.1$ & 2,5 para 12,1 & EUA \\
Oeste Europeu & 12,267 & $2,721.6$ & 0,8 para 3,7 & Noruega \\
\hline
\end{tabular}

Fonte: OPEC - Annual Statistical Bulletin 2014. 
Elaboração: GeoBrasil, Grupo de Pesquisa Geográfica Brasileira: História e Política (UERJ)

\section{Consumo}

$\mathrm{Na}$ geopolítica do petróleo, tão ou mais importante que a capacidade produtiva dos países ou o tamanho de suas reservas, é a sua sede de petróleo. É a necessidade de consumo energético dos países desenvolvidos e das regiões mais industrializadas do planeta, com a finalidade de suprir seus grandes mercados internos, que acabam por dar forma e dinâmica à complexa rede da indústria petrolífera mundial, criando e ordenando o espaço, e/ouregulando, através da força do capital, da persuasão, ou do aparato militar, territórios estratégicos em busca de segurança energética (HARVEY 2004; JUHASH, 2009). Neste sentido, a investigação da distribuição geográfica do consumo de petróleo mundial se converte em ferramenta da análise. Mais uma vez percebe-se que, ao longo da cadeia produtiva do petróleo, no sentido upstream - downstream, novas geografias vão surgindo. A geografia do consumo de petróleo mundial é completamente distinta da geografia das reservas mundiais de petróleo, e mesmo da geografia dos grandes produtores.

Tabela 4 - Maiores consumidores de petróleo (milhões de barris p/ dia, crudeoil) por países e regiões-2013

\begin{tabular}{|c|c|c|c|c|c|c|}
\hline País & Barris & $\begin{array}{c}\text { Membro } \\
\text { OPEC }\end{array}$ & BRICs & Região & Barris & $\begin{array}{c}\text { Países } \\
\text { Motores }\end{array}$ \\
\hline EUA & $18,899.9$ & & & $\begin{array}{l}\text { Total } \\
\text { Mundial }\end{array}$ & $90,005.5$ & EUA \\
\hline China & $10,067.8$ & & Sim & $\begin{array}{l}\text { Ásia e } \\
\text { Pacifico }\end{array}$ & $29,245.8$ & $\begin{array}{c}\text { China, Japão } \\
\text { e Índia }\end{array}$ \\
\hline Japão & $4,544.9$ & & & $\begin{array}{l}\text { América } \\
\text { do Norte }\end{array}$ & $21,193.6$ & EUA \\
\hline Índia & $3,698.3$ & & Sim & $\begin{array}{l}\text { Oeste } \\
\text { Europeu }\end{array}$ & $13,004.2$ & Alemanha \\
\hline Rússia & $3,435.4$ & & Sim & $\begin{array}{l}\text { América } \\
\text { Latina }\end{array}$ & $9,266.9$ & $\begin{array}{l}\text { Brasil e } \\
\text { México }\end{array}$ \\
\hline
\end{tabular}

Geo UERJ. Rio de Janeiro - Ano 16, no. 25, v.2, $2^{\circ}$ semestre de 2014, pp.419-457

ISSN: 1415-7543 E-ISSN: 1981-9021

http://www.e-publicacoes.uerj.br/index.php/geouerj 


\begin{tabular}{|c|c|c|c|c|c|c|}
\hline Brasil & $3,012.6$ & & Sim & $\begin{array}{l}\text { Orienta } \\
\text { Médio }\end{array}$ & $8,050.6$ & $\begin{array}{l}\text { Arábia } \\
\text { Saudita }\end{array}$ \\
\hline $\begin{array}{l}\text { Arábia } \\
\text { Saudita }\end{array}$ & $2,994.0$ & Sim & & $\begin{array}{l}\text { Leste } \\
\text { Europeu e } \\
\text { Eurásia }\end{array}$ & $5,694.7$ & Rússia \\
\hline Alemanha & $2,405.3$ & & & África & $3,549.8$ & Egito \\
\hline Canadá & $2,291.2$ & & & & & \\
\hline $\begin{array}{l}\text { Coréia do } \\
\text { Sul }\end{array}$ & $2,286.7$ & & & & & \\
\hline México & $2,105.1$ & & & & & \\
\hline
\end{tabular}

Fonte: OPEC - Annual Statistical Bulletin 2014.

Elaboração: GeoBrasil, Grupo de Pesquisa Geográfica Brasileira: História e Política (UERJ)

Observações: BRICs em sua formação clássica (O’NEILL, 2001).

A análise da Tabela 4 confirma a existência de dois grandes grupos: produtores e consumidores. América do Norte e Oeste Europeu lideram o consumo de petróleo mundial, superadas apenas pela Ásia, com a participação japonesa, e as gigantes emergentes: China e Índia. Do outro lado, Oriente Médio (apesar de relativo consumo da Arábia Saudita), América Latina(mesmo com Brasil e México), Leste Europeu e Eurásia (mesmo com a Rússia), e África, são as regiões com menor participação no consumo mundial de petróleo, embora sejam as maiores produtoras conforme.

A geografia do consumo do petróleo torna possível visualizar dois processos que são de extrema importância para o entendimento da ordem econômica mundial atual e para a compreensão das estratégias norte-americanas na geopolítica do petróleo. $\mathrm{O}$ primeiro, já citado, é o déficit energético norte-americano. Os EUA produziram em 2013, aproximadamente 7,4 milhões de barris de petróleo por dia, enquanto consumiram no mesmo período, em média, quase 18 milhões de barris por dia.O segundo, a aceleração do consumo energético dos BRIC. China, Índia, Rússia e Brasil, foram responsáveis por aproximadamente $22 \%$ do consumo mundial de petróleo em 2013. A Figura 1 permite visualizar aestagnação norte-americana no período 2009-2013 e o crescimento dos BRIC no mesmo intervalo. 
Consumo de Petróleo b/d - EUA X BRIC

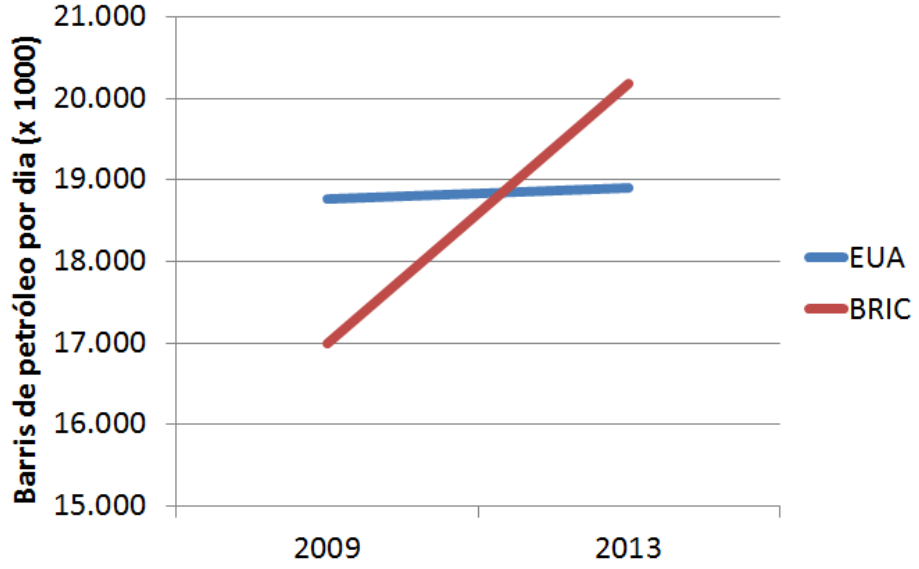

Figura 4 - Evolução do consumo de petróleo (oilcrude) EUA e BRICs.

Fonte: OPEC, 2014

Elaboração: GeoBrasil, Grupo de Pesquisa Geográfica Brasileira: História e Política (UERJ)

Maior consumidor de petróleo do mundo, os EUA sugaram, em 2013, em torno de 18 milhões de barris de petróleo por dia, para manutenção de seumercado interno. Número impressionante se comparados aos números chineses, potência emergente, que só em 2013 superou levemente os 10 milhões de barris diários. Outros países bem posicionados não superaram os 5 milhões de barris por dia. Os EUA, de 2009 a 2013 mantiveram praticamente a mesma média de consumo, próxima dos19 milhões de barris de petróleo por dia. Dados recentes apontam para um declínio das importações de petróleo por parte dos EUA, seja em virtude do ritmo lento da economia, seja por fatores políticos como o projeto de diminuição da dependência de petróleo do Oriente Médio e investimento na produção interna (FORNETTI, 2012). Isso não significa, no entanto, redução de consumo ou de produção.

Embora os números mudem, e no mercado mundial de petróleo, isso seja uma constante, a apresentação dos dados referentes ao consumo mundial do insumo, de acordo com o Boletim Estatístico Anual da OPEC, não difere de maneira importante das publicações similares da AIE ou dos quadros estatísticos das grandes companhias petrolíferas no cenário mundial como a BP por exemplo. Os relatórios estatísticos de 
2014 disponíveis apresentam dados sequenciais de 2009a2013, e acontecimentos bruscos de todas as ordens no cenário mundial (crises financeiras, desastres naturais, guerras, novas técnicas) podem, de um ano para o outro, imprimir mudanças, principalmente no consumo do petróleo. Em janeiro de 2013 o Instituto Americano de Petróleo (API) divulgou que a produção de petróleo nos EUA atingiu em 2012 a média de 6,4 milhões de barris por dia, o que seria o maior salto de produção na história norteamericana. Há previsões para 2013 de aumento de 900 mil barris diários (FOWLER, 2013). O declínio das importações norte-americanas de petróleo está associado, em parte, ao investimento em sua produção interna, recentemente alavancada pelo petróleo extraído do xisto (tightoil). Porém, o processo ainda é considerado em fase inicial, com riscos ambientais, e com custo elevado (COSTAS, 2012).

Já o consumo de petróleo em todos os países do BRICs vem aumentando ano após ano. China, Índia, Brasil e Rússia juntos elevaram seu consumo de petróleo de 16,9 milhões de barris de petróleo por dia em 2009, para 20,2 milhões em 2013. Um acréscimo de aproximadamente 3 milhões de barris. $\mathrm{O}$ aumento do consumo implica em uma maior preocupação com a segurança energética desses países em virtude da necessidade de manter seus respectivos crescimentos econômicos e suprir a demanda interna de energia.

Tratando-se de consumo de petróleo, faz-se necessário uma observação sobre o Japão. Terceiro maior consumidor de petróleo na atualidade, o Japão, dentre os cinco maiores territórios consumidores é aquele que apresenta maior participação de petróleo em sua matriz energética (42.5\%). Em números absolutos, EUA e China, consomem mais petróleo, porém o peso em suas matrizes energéticas deste recurso é menor. $\mathrm{O}$ Brasil apesar da sua potencialidade hídrica e dos biocombustíveis em sua matriz energética, ainda tem o petróleo como principal fonte de energia. Índia e China tem o carvão como principal recurso, enquanto a Rússia possui mais da metade de sua matriz energética dependente do gás natural. Ver Tabela 5.

Tabela 5 - Principais consumidores de petróleo (crudeoil) por país, e suas matrizes energéticas- 2009

\begin{tabular}{cccccccc}
\hline País & Petról & Gás & Carv & Nucle & Hidr & Biocombustí & Geotermal/solar/e \\
& eo & & ão & ar & o & veis & ólica \\
\hline
\end{tabular}

Geo UERJ. Rio de Janeiro - Ano 16, no. 25, v.2, $2^{\circ}$ semestre de 2014, pp.419-457

ISSN: 1415-7543 E-ISSN: 1981-9021

http://www.e-publicacoes.uerj.br/index.php/geouerj 


\begin{tabular}{|c|c|c|c|c|c|c|c|}
\hline Japão & $42.5 \%$ & $\begin{array}{c}17.1 \\
\%\end{array}$ & $21.5 \%$ & $15.4 \%$ & $1.4 \%$ & $1.4 \%$ & $0.8 \%$ \\
\hline Brasil & $40.2 \%$ & $7.2 \%$ & $4.6 \%$ & $1.4 \%$ & $\begin{array}{c}14.2 \\
\%\end{array}$ & $32.1 \%$ & $0.3 \%$ \\
\hline EUA & $37.1 \%$ & $\begin{array}{c}24.7 \\
\%\end{array}$ & $22.5 \%$ & $10.0 \%$ & $1.1 \%$ & $3.9 \%$ & $0.8 \%$ \\
\hline $\begin{array}{l}\text { Mund } \\
\text { o }\end{array}$ & $32.8 \%$ & $\begin{array}{c}20.9 \\
\%\end{array}$ & $27.2 \%$ & $5.8 \%$ & $2.3 \%$ & $10.2 \%$ & $0.8 \%$ \\
\hline Índia & $23.6 \%$ & $7.2 \%$ & $42.3 \%$ & $0.7 \%$ & $1.4 \%$ & $24.5 \%$ & $0.3 \%$ \\
\hline $\begin{array}{l}\text { Rússi } \\
\text { a }\end{array}$ & $21.3 \%$ & $54 \%$ & $14.7 \%$ & $6.6 \%$ & $2.3 \%$ & $1.0 \%$ & $0.1 \%$ \\
\hline China & $16.8 \%$ & $3.3 \%$ & $67.3 \%$ & $0.8 \%$ & $2.3 \%$ & $9.0 \%$ & $0.5 \%$ \\
\hline
\end{tabular}

Fonte: http://www.iea.org/stats/index.asp.

Elaboração: GeoBrasil, Grupo de Pesquisa Geográfica Brasileira: História e Política (UERJ)

\section{Refino: a centralidade das companhias nacionais e internacionais de petróleo}

Tanto as reservas, quanto a produção são influenciadas por determinações físicas, e mais especificamente pela geologia do subsolo e consequente localização das bacias sedimentares ricas em petróleo, onde a sua exploração e produção são feitas "in loco". Já o consumo, só pode ser em parte compreendido, ao analisarmos os fluxos comerciais do petróleo, a composição das matrizes energéticas dos países, seus dados demográficos, seus graus de desenvolvimento industrial, suas histórias, e, a distância entre território consumidor e as localizações geológicas dos grandes sistemas petrolíferos.O refino está ligado à transformação do petróleo em produtos finais para variados setores da economia, sendo assim, torna-se importante a visualização geográfica da transformação do petróleo.

Tabela 6 - Maior capacidade de refino (milhões de barris por dia, crudeoil) - por países e regiões -2013

\begin{tabular}{lcc|ccc}
\hline Países & Barris & $\begin{array}{c}\text { Membro } \\
\text { OPEC }\end{array}$ & Região & Barris & $(\%)$ \\
\hline
\end{tabular}

Geo UERJ. Rio de Janeiro - Ano 16, nº. 25, v.2, $2^{\circ}$ semestre de 2014, pp.419-457

ISSN: 1415-7543 E-ISSN: 1981-9021

http://www.e-publicacoes.uerj.br/index.php/geouerj 


\begin{tabular}{lcl|llc}
\hline EUA & $17,815.4$ & Não & Total Mundial & $94,473.9$ & 100,0 \\
China & $11,787.3$ & Não & Ásia e Pacífico & $30,343.4$ & 32,1 \\
Rússia & $5,754.0$ & Não & América do Norte & $19,865.1$ & 21,0 \\
Japão & $4,339.7$ & Não & Oeste Europeu & $14,097.6$ & 14,9 \\
Índia & $4,319.0$ & Não & Leste Europeu e & $10,087.7$ & 10,6 \\
Coréia do Sul & $2,958.5$ & Não & América Latina & $8,742.4$ & 9,2 \\
Arábia Saudita & $2,507.0$ & Sim & Orienta Médio & $7,877.3$ & 8,3 \\
Alemanha & $2,417.2$ & Não & África & $3,460.5$ & 3,6 \\
Itália & $2,115.7$ & Não & & & \\
Brasil & $2,102.0$ & Não & & & \\
Canadá & $2,049.7$ & Não & & & \\
Irã & $1,715.0$ & Sim & & & \\
México & 1.690 .0 & Não & & & \\
Reino Unido & $1,524.4$ & Não & & & \\
França & $1,508.4$ & Não & & & \\
Singapura & $1,344.5$ & Não & & & \\
\hline
\end{tabular}

Fonte: OPEC - Annual Statistical Bulletin 2014. Elaboração: GeoBrasil, Grupo de

Pesquisa Geográfica Brasileira: História e Política (UERJ)

A distribuição geográfica da capacidade de refino do petróleo é semelhante à distribuição geográfica do consumo, seja na escala dos países ou das regiões, muito em virtude dos países consumidores desenvolverem seus parques de refino para suprirem suas demandas internas, e/ou estarem vinculados às atividades das grandes companhias internacionais de petróleo.

$\mathrm{Na}$ geopolítica do petróleo, as grandes companhias petrolíferas são agentes de primeira grandeza, possuem mais reservas que muitos estados nacionais, produzem, refinam, estocam e transportam todo o petróleo do planeta. As maiores reservas do mundo estão sob o controle das companhias nacionais de petróleo (NationalOilCompanies - NOCs), petrolíferas estatais, como a Saudi Aramco da Áraba Saudita, NIOC (NationalIranianOilCompany) no Irã, PDVSA na Venezuela, a Russa GAZPRON, e a Petrobras no Brasil. 
O peso geopolítico dessas empresas estatais é um fato, pois estima-se que mais de $77 \%$ das reservas mundiais de petróleo estejam sob a administração das NOCs (JAFFE \& SOLIGO, 2007; MACHADO \& REIS, 2011), com previsões de chegar a 90\% nos próximos 40 anos (HOYOS, 2007). Por outro lado, as companhias internacionais de petróleo (InternationalOilCompanies - IOCs), principalmente as supermajors British Petroleum, Chevron, ExxoMobil e Royal Dutch Shell, mantiveram seu peso geopolítico no mercado mundial de petróleo, expandindo suas atividades pelo mundo através de fusões e aquisições e migrando para atividades de maior valor agregado, conteúdo tecnológico e logístico dentro da cadeia produtiva de petróleo, como os setores petroquímico e de transporte (AL-NAIMI, 2006). Desta maneira, a análise da ação das companhias petrolíferas estabelece uma linha direta com a ação geopolítica dos estados nacionais, seja através de empresas privadas como no caso norte-americano, ou através de empresas estatais, como no caso brasileiro com a Petrobras S.A.

Tabela 7 - Maiores companhias em atividades integradas em petróleo e gás - 2012

\begin{tabular}{|c|c|c|}
\hline Companhia & País relacionado & Companhia \\
\hline Exxon Mobil Corp & EUA & Privada \\
\hline Royal Dutch Shell plc & Holanda & Privada \\
\hline Chevron Corp & EUA & Privada \\
\hline BP plc & Reino Unido & Privada \\
\hline OJSC Gazpron & Rússia & Estatal \\
\hline Statoil ASA & Noruega & Privada \\
\hline Total AS & França & Privada \\
\hline PetroChinaCoLtd & China & Estatal \\
\hline RosneftOilCo & Rússia & Estatal \\
\hline OJSC LUKOIL OilCo & Rússia & Estatal \\
\hline China Petroleum\&ChemicalCorp & China & Estatal \\
\hline Ecopetrol AS & Colômbia & Estatal \\
\hline OAO TNK-BP Holding & Rússia & Estatal \\
\hline EniSpA & Itália & Privada \\
\hline Petróleo Brasileiro AS - & Brasil & Estatal \\
\hline
\end{tabular}

Geo UERJ. Rio de Janeiro - Ano 16, nº. 25, v.2, $2^{\circ}$ semestre de 2014, pp.419-457 ISSN: 1415-7543 E-ISSN: 1981-9021 http://www.e-publicacoes.uerj.br/index.php/geouerj 


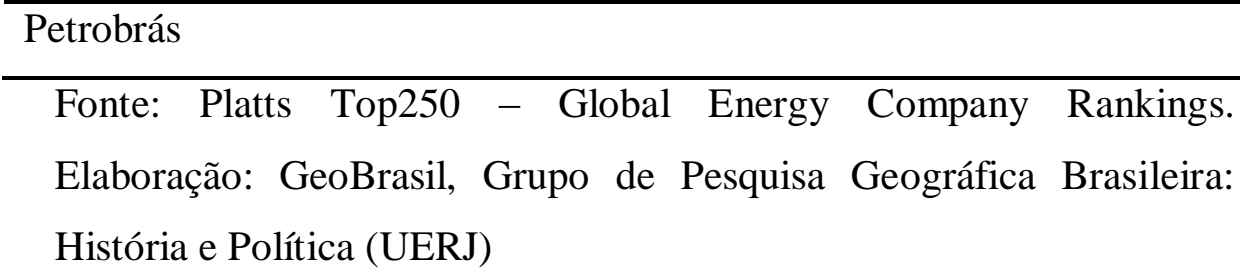

As tradicionais companhias internacionais de petróleo com suas superestruturas e redes comerciais possuem maior presença geográfica no mundo do que as companhias estatais. Por consequência, suas diretrizes e ações possuem alto potencial geopolítico e são fundamentais para a segurança energética de seus países de origem.

A presença norte-americana no Oriente Médio e o renovado interesse na América do Sul recebem o verniz da luta pela democracia e questões humanitárias como foi no Iraque e é atualmente na Síria, e do combate ao narcotráfico internacional como na Colômbia. Mas o cerne da questão é o interesse pelo recursos energéticos estratégicos. Para ambos os casos a resposta é a militarização das áreas a fím de assegurar, de maneira imediata, a continuidade do fornecimento de recursos energéticos, e a médio e longo prazogarantir posições estratégicas em regiões de interesse econômico.

Na América do Sul, além do Brasil e da Venezuela, com suas gigantescas reservas de petróleo, Colômbia, Equador, Bolívia e Peru também possuem reservas de petróleo e gás. Os EUA têm se aproximado dos países andinos e é o principal destino das exportações de petróleo da Venezuela. Luiz Alberto Moniz Bandeira (2008) correlaciona inclusive a restauração da IV Frota e a renovação do interesse norteamericano no Atlântico Sul, à descoberta das jazidas do pré-sal na plataforma continental brasileira, associado à aproximação da China como parceira econômica dos países da América do Sul como potencial comprador de insumos energéticos.

Neste contexto, e especificamente em relação à posição geopolítica do Brasil na América do Sul, a Petrobrás se configura como peça chave no jogo de poder regional, por seu tamanho, diversificação, expertise tecnológica, mas sobretudo pela sua íntima ligação com as estratégias de política interna (controle de inflação, desenvolvimento da cadeias produtivas) e política externa (posição de liderança regional) do governo brasileiro. Atualmente a Petrobras possui atividades na Venezuela, Colômbia, Peru, Bolívia, Paraguai, Chile, Argentina, e Uruguai. Este papel é mais nítido nos casos das 
companhias estatais de petróleo. Caso semelhante ocorre com a GAZPRON e seu peso geopolítica na Europa e Ásia, a favor da Rússia. A diferenciar as NOCs das IOCs, os investimentos diretos feitos por esses governos em suas companhias de petróleo, no desenvolvimento de infraestrutura da cadeia produtivas do setor (embarcações, plataformas, refinarias, dutos, estradas), e pelas novas modalidades de contrato que procuram assegurar o controle de suas reservas e produção (JAFFE \& SOLIGO, 2007, BROS \& RICHARD, 2011, MACHADO \& REIS, 2011, MACHADO, 2012; RAFAEL, 2012).

\section{O novo mapa do petróleo, a emergência pan-americana}

Considera-se para fins conceituais neste artigo, que regiões emergentes são aquelas que até recentemente, não possuíam reservas de petróleo consideráveis, em comparação com as regiões tradicionais, especialmente o Oriente Médio. Algumas dessas regiões chegaram ao limite de suas reservas, como no caso norte-americano nos anos 70, ou não havia ainda acumulado os meios técnico-científicos para exploração de suas potencialidades energéticas não convencionais, como no caso brasileiro com o présal, e o canadense com as areias betuminosas, e o próprio EUA com xisto.

Também para fins conceituais, explica-se que o termo "não convencionais", associado ao petróleo ou ao gás, está relacionado a métodos de extração mais complexos e custosos às atividades de exploração, produção e refino. Também são considerados "não convencionais" os óleos de qualidade inferior, de difícil acesso, que da mesma formam encarecem todo o processo produtivo (HENRIQUE JR; SZKLO, SCHAEFFER, 2007).Assim, neste artigo, são consideradas fontes de petróleo não convencionaiso pré-sal brasileiro, as areias betuminosas canadenses e o óleo de xisto norte-americano.

\section{O petróleo e gás do xisto norte-americano}

Segundo Maugeri (2012, p. 38), os EUA serão os responsáveis principais pelo reordenamento da geografia e da geopolítica do petróleo mundial. Esta "revolução" estaria ligada a exploração do óleo e do gás provenientes do xisto, que elevariam a produção norte-americana, em 2020, para mais de 10 milhões de barris de petróleo por

Geo UERJ. Rio de Janeiro - Ano 16, ${ }^{\circ}$. 25, v.2, $2^{\circ}$ semestre de 2014, pp.419-457

ISSN: 1415-7543 E-ISSN: 1981-9021

http://www.e-publicacoes.uerj.br/index.php/geouerj 
dia,dobrando sua produção atual e superando as atuais potências produtoras, Rússia e Arábia Saudita. Tratando-se especialmente dos EUA, que são a peça central da indústria petrolífera mundial,por sua alta dependência de consumo de petróleo, e mantidas as previsões de aumento de produção de petróleo e gás do xisto, a geopolítica do petróleo sofreria sérios impactos.Haveria oscilações no peso estratégico de territórios tradicionais, e nas suas relações comerciais ligadas à indústria do petróleo. Estima-se que somente as reservas de gás, sob o solo norte-americano provenientes do xisto seja de 24,5 trilhões de metros cúbicos. Hoje as reservas de gás natural nos EUA estão na casa dos 8,7trilhões de metros cúbicos (OPEP, 2014). Estas projeções estão baseadas na infraestrutura instalada no território norte-americano. Sua imensa e altamente distribuída rede de dutos, que transportam petróleo e gás, já está adaptada tanto ao mercado interno, quanto a mercado global e ao crescimento da produção interna de petróleo e gás.Ver Figura 5.

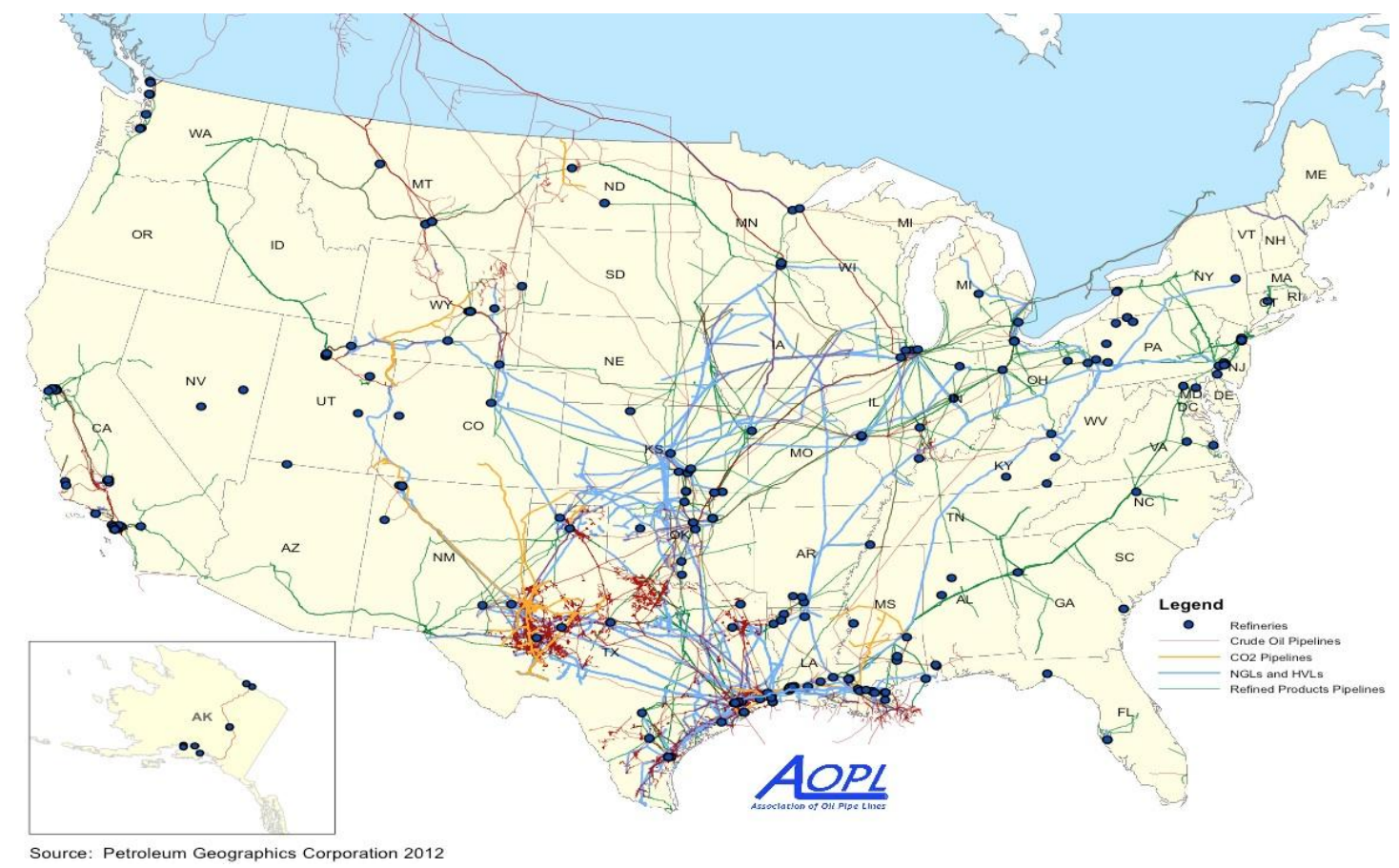

Figura 5 - Infraestrutura de dutos EUA 2012

Fonte: http://www.aopl.org/

Não só a dependência energética americana estariaem pauta, como também seu novo papel na geografia e geopolítica do petróleo, como exportador de petróleo e gás. A Rússia mantem, muito em virtude da proximidade geográfica, embora não Geo UERJ. Rio de Janeiro - Ano 16, ${ }^{\circ}$. 25, v.2, $2^{\circ}$ semestre de 2014, pp.419-457

ISSN: 1415-7543 E-ISSN: 1981-9021

http://www.e-publicacoes.uerj.br/index.php/geouerj 
exclusivamente, relações energéticas com a Europa, que é, em grande parte, dependente do gás russo. A despeito desta vantagem geográfica, a emergência norte-americana na produção de gás, em um mercado tão globalizado, implicaria certamente na reestruturação das relações energéticas entre a Rússia e a Europa (YERGIN, 2012).Este é apenas um exemplo de uma variada gama de consequências reestruturantes que a emergência energética norte-americana poderá acionar.

$\mathrm{Na}$ base desse processo, está a tecnologia que pode provocar mudanças no cenário energético mundial: o fraturamento hidráulico (fracking) e a perfuração horizontal (horizontal drilling). Somente com o amadurecimento e a fusão dessas duas técnicas, vemsendo possível extrair o gás e o petróleo das rochas de xisto. Através da injeção de uma solução de água, areia, e produtos químicos, em alta pressão, em um tubo que após percorrer certa profundidade (em média 2 quilômetros) verticalmente, passa a perfurar a rocha de xisto no sentido horizontal, a rocha é fraturada em vários segmentos, e o gás e o óleo, até então presos na rocha, são recolhidos pela tubulação e impulsionados para cima. A tecnologia já existia, mas agora é comercialmente viável.

Há um intenso debate sobre os riscos ambientais provocados pelo faturamento hidráulico. Contaminação do solo, dos lençóis freáticos, utilização excessiva de água (VENGOSH, 2011). Países como a França, Bulgária, e Suíça proibiram ou estudam a proibição das técnicas de fraturamentohidráulico em seus territórios. No entanto, a experiência norte-americana, a despeito de todas as dúvidas quanto aos problemas socioambientais, parece estar estimulando o mercado do gás de xisto pelo mundo. Polônia, África do Sul, China e Argentina, que possuem grandes reservas a serem desenvolvidas, já começaram a organizar seus projetos de exploração do gás de xisto (FOOD\&WATER WATCH, 2012).

\section{As areias betuminosas canadenses}

De acordo com o BP StatisticalReviewof World Energy de 2012, que diferentemente dos relatórios estatísticos atuais da OPEP e da IEA, contabiliza o petróleo oriundo das areias betuminosas do Canadá em seus quadros estatísticos, este país, possui hoje, a terceira maior reserva de petróleo provada do mundo, com 175 bilhões de barris, atrás apenas de Venezuela e Arábia Saudita. Vizinho do maior consumidor de petróleo do planeta, o Canada exporta quase que a totalidade de seu 
petróleo para os EUA. Estima-se que com o petróleo oriundo das areias betuminosas o Canada responderá, nos próximos anos, por 36\% das importações de petróleo feitas pelos EUA.

O potencial das areias betuminosas do Canada, concentrado na província de Alberta, está interligado à economia norte-americana através de uma rede de dutos, que escoa a produção do óleo pesado para as refinaras norte-americanas. O principal oleoduto a interligar os dois países é o Keystone I, com aproximadamente 3.400 quilômetros de extensão,que conecta a província de Alberta no Canadaaté o Estado de Illinois nos EUA. O oleoduto cruza os estados centrais norte-americanos, de Dakota do Norte, Dakota do Sul, parte de Nebrasca, Kansas, e Missouri, para ser refinado em Illinois. Há uma extensão do duto até Oklahoma, denominado KeystoneCushingExtension, que liga Keystone I a partir de Nebrasca, perfazendo aproximadamente 480 quilômetros até a cidade de Cushing em Oklahoma,pólo de armazenamento e distribuição de petróleo nos EUA. Também partindo de Alberta um terceiro oleoduto com 1.600 quilômetros cruza a fronteira de Minnesota para atingir o noroestedo Estado deWisconcin, na cidade portuária de Superior, onde o óleo é refinado.

Mas esta rede de dutos não responde às expectativas de aumento de produção do governo canadense, e particularmente da TransCanada, gigante do ramo da infraestrutura de energia na América do Norte. Interessada em maximizar o fornecimento de petróleo para os EUA, em 2008 a TransCanada apresentou o projeto Keystone $X L$, que levaria o petróleo das areias betuminosas do Canada até as refinarias norte-americanas do Golfo da costa do Texas. O que poderia resultar em um grande acordo entre o Canadá e os EUA, com o fortalecimento de laços energéticos, e ganhos consideráveis para a TransCanada, e para o governo Canadense, encontrou forte resistência da comunidade norte-americana e mundial engajada nas causas ambientais e crítica da construção do óleoduto de 2.700 quilômetros. Após uma primeira rejeição do projeto, em 2008, por falta de garantias ambientais e estudos mais aprofundados do impacto da construção do oleoduto, o projeto foi novamente rejeitado pelo Presidente Barack Obama em janeiro de 2012 (GERALDES, 2012). Com o apoio de 53 senadores, em janeiro de 2013, o projeto voltou as mãos de Obama, agora revisado pela TransCanada. O projeto é polêmico em virtude de ser o processo de extração do 
petróleo das areias betuminosas o mais sujo e poluente da indústria do petróleo. O oleoduto também cruzaria a região das zonas húmidas dos Estados Unidos no Estado de Nebrasca, o maior e mais complexo ecossistema do país (DROITSCH, 2012).

Diante da possibilidade de não consecução dos projetos de aumento da integração energética com os EUA, o governo canadense e a TransCanadapassaram a construir caminhos alternativos para escoar sua produção, agora diretamente no mercado global. Seriam dois oleodutos,que partindo de Alberta chegariam a costa do pacífico, o Northern Gateway (previsto para iniciar as atividades em 2015) e a TransMountain (previsto para começar as atividades em 2017), respectivamente ao norte e ao sul da província de British Columbia. O objetivo seria o mercado asiático. Há outro projeto, o East Coast, ainda em elaboração, que chegaria à costa atlântica canadense, partindo de Alberta até St. John, visando o fornecimento para o mercado europeu.

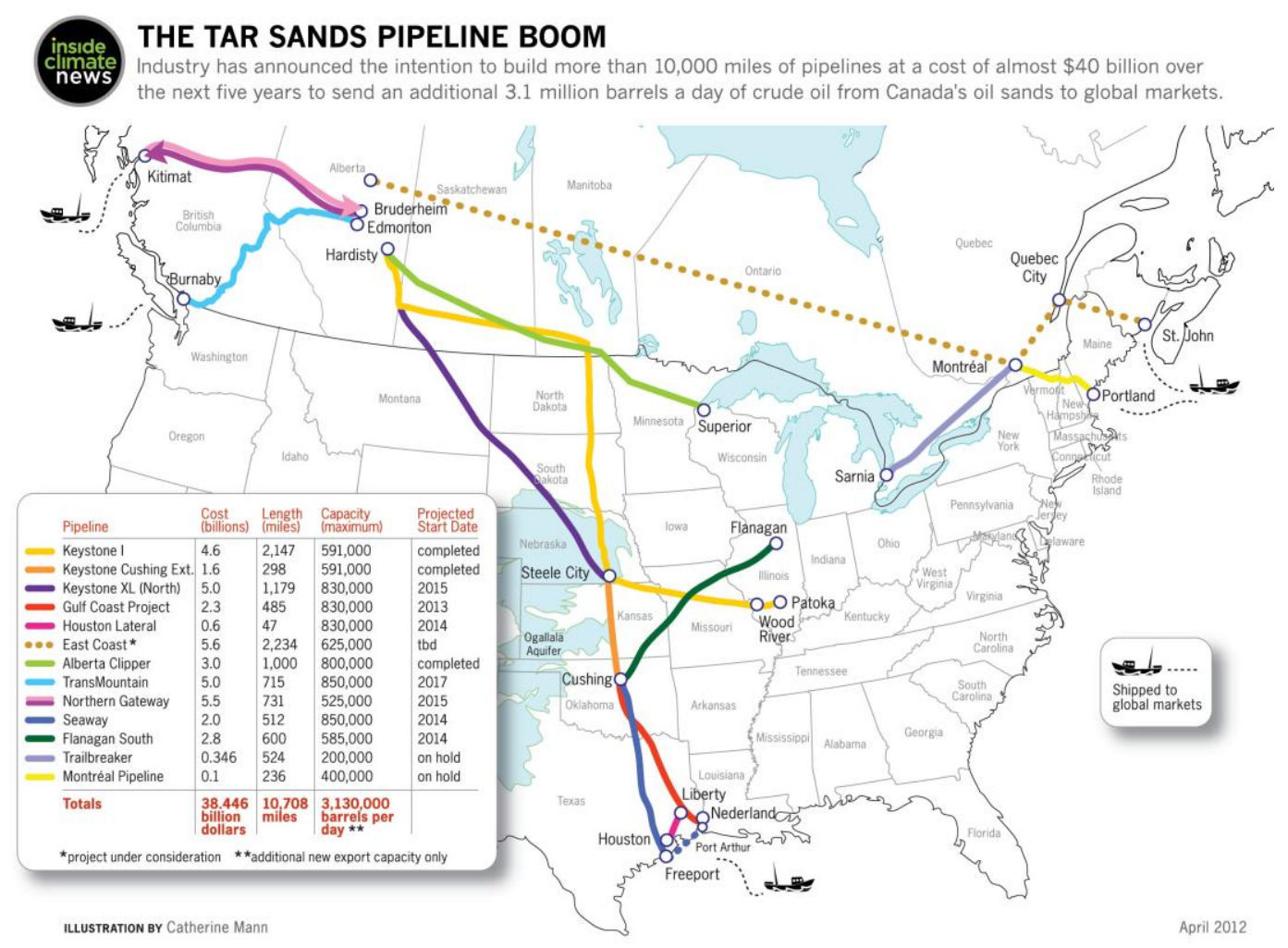

Figura 6 - Construção de dutos visando mercado global, Canadá 2012.

Fonte: www.insideclimatenews.org 
A despeito das estratégias de atuação canadense na geopolítica do petróleo, no caso específico das areias betuminosas, a comunidade internacional, através de organizações voltadas para defesa do meio-ambiente surge como ator de peso. Em fevereiro de 2013 milhares de manifestantes reunidos em Washington, no movimento "Avante pelo Clima", pediam ao Presidente Obama para que rejeitasse mais uma vez o projeto do oleoduto Keystone XL. Um tenso debate entre aqueles que defendem o meioambiente e aqueles que enxergam na construção do oleoduto a oportunidade de criação de milhares de empregose a segurança energética dos EUA, vai prosseguir até que o Presidente Obama decida sobre a questão.

A tecnologia envolvida na produção do petróleo das areias betuminosas é recente, e foi responsável direta pelo o aumento das reservas provadas no Canadá. A Drenagem Gravitacional Auxiliada por Vapor (SAGD) consiste na injeção devapor superaquecido nos poços para liquefação do betume, que é extremamente viscoso,possibilitando o seu bombeamento para a superfície (BARILLAS, 2005).A SAGD quintuplicou o volume de betume possível de ser extraído no Canadá (VALOR ECONOMICO, 2012).

\section{O pré-sal brasileiro}

No ano de 2006, o Brasil, através da Petrobras em parceria com as empresas estrangeiras British Gás, Repsol e Galp, descobriu a existência de petróleo a 7 mil metros de profundidade na camada pré-sal, sob uma camada de sal com espessura média de 2 mil metros,e a 300 quilômetros da costa, no Atlântico Sul. Em 2007, o governo brasileiro anunciava a descoberta. Era uma gigantesca reserva estimada entre 5 e 8 bilhões de barris de petróleo, no então denominado campo de Tupi (atualmente Lula), na Bacia de Santos. Iniciou-se então o desafio brasileiro de exploração e produção do petróleo da camada pré-sal. Estima-se que o polígono do pré-sal, que se estende do litoral do Espírito Santo até o litoral de Santa Catarina, com aproximadamente $150 \mathrm{mil}$ quilômetros quadrados, contenha aproximadamente 1,6 trilhão de metros cúbicos óleo e gás. 


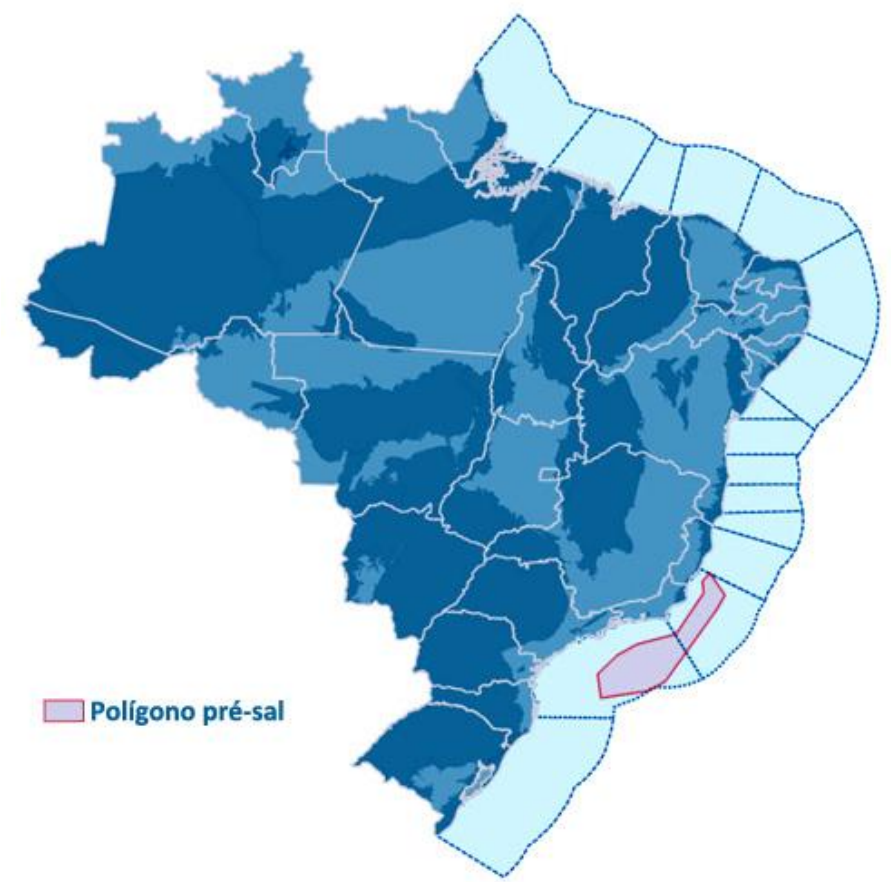

Figura 7 - Polígono do pré-sal brasileiro.

Fonte: www.anp.gov.br

Com experiência em atividades offshore $(65 \%$ das atividades offshore da Petrobras estão sob uma lâmina d'água de pelo menos 400 metros), a Petrobras especializou-se na exploração de petróleo em águas profundas e ultraprofundas.

Tabela 8 - Evolução dos campos exploratórios brasileiros por profundidade (metros)

\begin{tabular}{lcccc}
\hline Campos & Ano & Camada & $\begin{array}{c}\text { Profundidade } \\
\text { (metros) }\end{array}$ & Bacia \\
\hline Enchova & 1977 & Pós-Sal & 2.696 & Campos \\
Piraúna & 1983 & Pós-Sal & 2.825 & Campos \\
Marimbá & 1988 & Pós-Sal & 3.318 & Campos \\
Marlim & 1992 & Pós-Sal & 2.930 & Campos \\
Marlim & 1994 & Pós-Sal & 3.230 & Campos \\
Sul & & & & Campos \\
Marlim & 1997 & Pós-Sal & 3.167 & \\
Sul & & & & \\
\hline
\end{tabular}

Geo UERJ. Rio de Janeiro - Ano 16, no. 25, v.2, $2^{\circ}$ semestre de 2014, pp.419-457 ISSN: 1415-7543 E-ISSN: 1981-9021 http://www.e-publicacoes.uerj.br/index.php/geouerj 


\begin{tabular}{lcccc}
\hline Roncador & 1999 & Pós-Sal & 3.759 & Campos \\
Roncador & 2003 & Sal & 4.343 & Campos \\
Lula & 2007 & Pré-Sal & 7.000 & Santos \\
(Tupi) & & & &
\end{tabular}

Fonte: http://www.petrobras.com.br/minisite/presal/pt/cada-vez-mais-fundo/ Elaboração: GeoBrasil, Grupo de Pesquisa Geográfica

Brasileira: História e Política (UERJ)

Mas apesar do knowhowda Petrobras, os desafios técnicos e logísticos para exploração do pré-sal são gigantescos.Vão dos obstáculos de engenharia para perfuração da extensa camada de sal até o transporte de equipamento e trabalhadores da costa para as plataformas. Só na Bacia de Campos são contabilizadas,em média, 60 mil viagens de helicóptero por mês para o translado dos trabalhadores (GALL, 2011), a uma distância média de 100 quilômetros da costa. Para efeito de comparação, a área do présal está a uma distância 3 vezes maior. Ainda serão necessários centenas de superpetroleiros e barcos de apoio, multiplicar por 5 o número de plataformas de perfuração e de produção, viabilizar a construção de centenas de quilômetros de gasodutos submarinos, construção de complexas refinarias e etc. Há gargalos estruturais que vãoda falta de infraestrutura básicado paísà escassez de mão de obra qualificadade nível superior e técnico.A fim de superar esses desafios, a Petrobras projetou em seu Plano de Negócios 2012-2016 investimentos no valor de $\mathrm{R} \$ 416,5$ bilhões. $60 \%$ desse valor estão destinadosà área de exploração e produção, sendo $\mathrm{R} \$ 125$ bilhões para investimentos no pré-sal. (PN 2012-2016 Petrobras, 2012). Por sua parte, o governo brasileiro tem investido em programas específicos, como o PROMINP (Programa de Mobilização da Indústria Nacional de Petróleo e Gás) procurando atuar em setores estratégicos para suprir a demanda crescente da indústria petrolífera, como o fomento as pequenas e médias empresas, na qualificação da mão de obra e na capacitação da indústria nacional voltados para o mercado de petróleo e gás.

No que tange ao ambiente global, o advento do pré-sal proporcionou ao governo brasileiro a oportunidade ideal para reestruturação do marco regulatório do petróleo que em 1997 havia quebrado o monopólio da Petrobras. Em nome segurança energética e da projeçãode uma nova posição geopolítica do Brasil no cenário energético e econômico 
mundial, foi criado, em 2010, um novo marco regulatório do setor petrolífero.Comnovas regras de exploração e produção de petróleo e gás natural no présal e em áreas consideradas estratégicas pela União, estabelecendo a lei de partilha de produção em substituição ao sistema de concessões, e tornando obrigatória a participação da Petrobras como operadora e sócia de todo e qualquer futuro consórcio formado dentro da área do pré-sal.

Em 2011 a produção diária de petróleo no pré-sal era de 167,5 mil barris, correspondendo a 7,5\% da produção nacional (ANP, 2012). Esse número chegou a 376 mil em junho de 2013 (ANP, 2013). Estima-se que com a evolução da produção nas áreas do pré-sal, o Brasil dobrará sua produção diária, chegando a 4,5 milhões de barris por dia, dentro de um período de 8 a 10 anos (MAUGERI, 2012). Será necessário confrontar este patamar de produtividade com o crescimento econômico nacional, o comportamento da indústria, e a demanda interna de energia para mensurar se o Brasil terá excedente de produção de petróleo, e assim se converter, no futuro, em um exportador da commodity.

\section{O eixo pan-americano: breves cenários}

Sendo assim, EUA,Canadá e Brasil, confirmadas as projeções de elevação de suas produções de petróleo, adicionarão novos fluxos de exportação de petróleo ao mercado mundial, concorrentes entre si, mas também, confrontando com poderosas zonas de influência, principalmente da Rússia e da região do Oriente Médio. Ver Figura 8. 


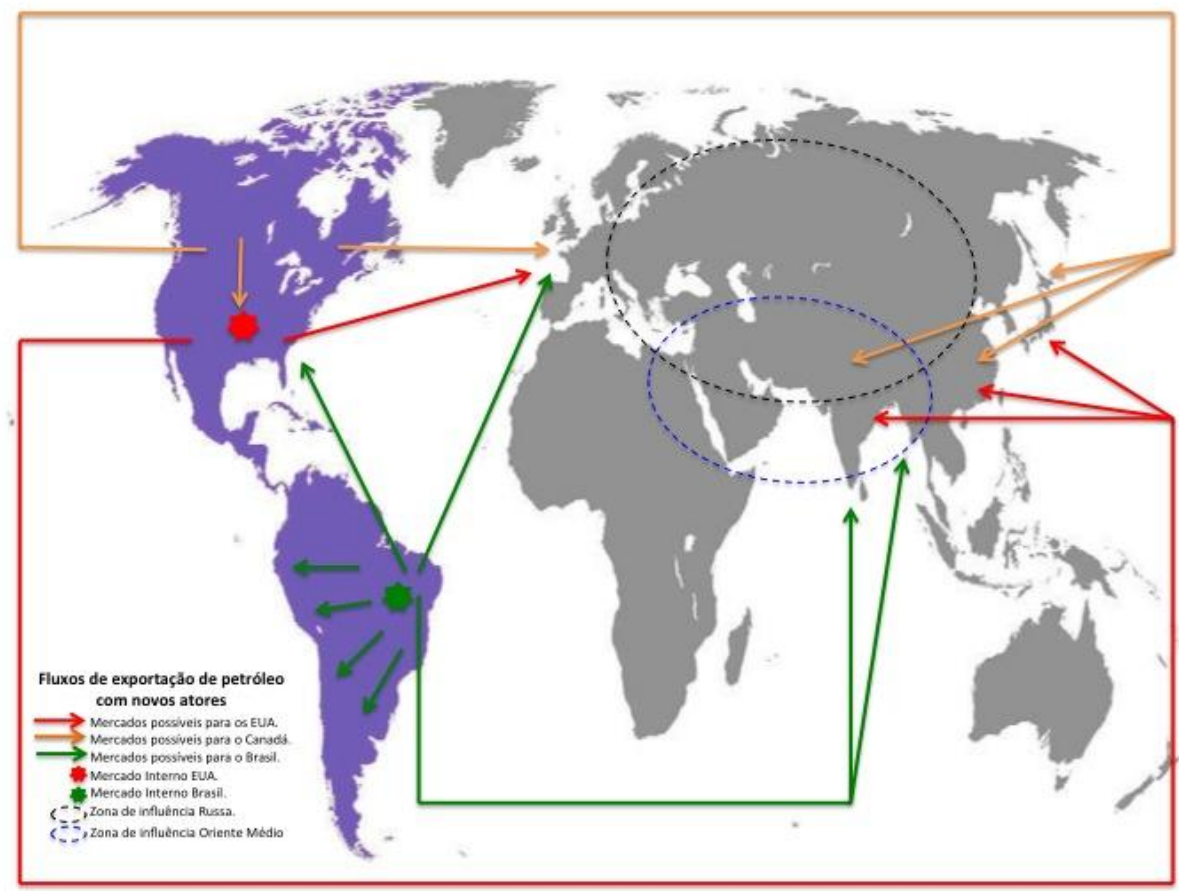

Figura 8 - Cenários de concorrência possíveis com a emergência de EUA, Canadá e Brasil Elaboração: GeoBrasil

Ao analisarmos os países, os cenários possíveis seriam:

1. Canadá. Mercados consumidores alvo: EUA, Oeste Europeu, Japão, China.

2. EUA. Mercados consumidores alvo: Mercado Interno (estabelecido), Oeste Europeu, Japão, China.

3. Brasil. Mercados consumidores alvo: Mercado Interno (em crescimento), EUA, Oeste Europeu, Japão, China, América do Sul (decisão estratégica).

Diante das expectativas de atuação dos três países analisados neste artigo, algumas linhas de ação, e de comportamento geopolítico se estabelecem fortemente, tendo a geografia forte influencia nesse processo:

A) no caso canadense, sua posição fronteiriça com a maior potencia consumidora do mundo, e as grandes reservas de petróleo oriundas das areias betuminosas, apontam para uma lógica parceria energética com EUA. Outros mercados, como europeu e asiático, seriam estratégias secundárias, embora importantes, em 
virtude de uma perigosa dependência de focar em apenas um mercado a escoação de sua produção.

B) No caso norte-americano, a segurança energética sempre foi uma questão de estado, e tem norteado a geopolítica norte-americana no Oriente Médio. A gigantesca placa de xistoMarcellus, parece ter potencialidade para reordenar esse cenário, garantindo aos americanos a autossuficiência energética, o que implicará na redefinição política do papel tradicionalmente desempenhado pelos EUA no Oriente Médio. Posicionado entre Canadá e México, os EUA, além da sua própria produção de petróleo, poderá contar com a produção dos seus vizinhos ao norte e ao sul, para complementar o fornecimento energético necessário para manutenção de seu mercado interno.

C) O Brasil, já detentor de uma posição de liderança econômica na América do Sul, poderá solidificar sua liderança regional com o advento do pré-sal. O crescimento econômico da América do Sul significaria uma oportunidade impar para o Brasil direcionar sua produção de petróleo. Iniciativas como o IIRSA com perspectivas de seus fluxos comerciais e criação de cadeias produtivas apontam para um processo de integração favorável as interesses brasileiros. O comportamento venezuelano, atualmente com enorme potencial, no entanto com pouca efetividade produtiva, deverá ser sempre observado quanto às estratégias regionais brasileiras.

\section{Considerações finais}

Como pode ser observado, a discussão geopolítica a respeito do pré-sal ainda não atingiu um corpo denso de contribuições teóricas dado o frescor da temática. Embora possam ser registradas iniciativas como as de Frédéric Monié e Jacob Binsztok (2012), de Claudio Pinho (2010), de Rosélia Piquet (2011), de João Paulo dos Reis Velloso (2010) e do Itamaraty. Este estudo procurou dar uma contribuição ao debate geopolítico do petróleo, chamando atenção para as novas fontes não convencionais de petróleo na América, destacando, particularmente, o papel do Brasil e o pré-sal brasileiro no cenário geopolítico mundial.

As novas descobertas de petróleo de fontes não convencionais na América, possivelmente vão promover alterações na geopolítica energética mundial, em função da manutenção do petróleo como principal fonte de energia pelo menos nas próximas décadas. Não é demais lembrar que as fontes alternativas de energia ainda vão demorar 
em apresentar sucesso efetivo(MAUGERI, 2012).Conforme foi exposto, os processos que envolvem as novas fronteiras exploratórias na indústria do petróleo apontam para um período longo de boa oferta desta commodity no mundo, com surgimento de novos atores, de pesos variados, no jogo energético mundial. Efetiva-se, assim, a importância estratégica do petróleo, já que a sociedade moderna faz uso intensivo de variado número de seus subprodutos, e a premência da reestruturação das relações políticas e econômicas entre os territórios envolvidos neste mercado. As novas tecnologias de exploração, produção e refino tendem, de certa maneira, a tornar o petróleo um insumo mais democrático, no sentido da ampliação do número de territórios que poderão passar a explorar reservas não convencionais, desde que as condições materiais dos países proporcionem a capacidade de realizar suas potencialidades, seja por intermédio de um estado indutornacional desenvolvimentista, ou através de um viés neoliberal de atração de companhias internacionais do setor (MAUGERI, 2012).

É provável que as regiões tradicionais percam centralidade do mercado mundial de petróleo, poiso continente americano, que já contava com as reservas venezuelanas, terá seu papel geopolítico redefinido, principalmente com a emergência energética do Canadá e a reestruturação energética norte-americana. Estes dois países, muito em virtude, não só do tamanho de suas reservas de óleo e gás não convencionais, mas, sobretudo, pelos sistemas de infraestrutura já instalados em seus territórios, possuem condições de gerar um maior impacto no reordenamento da geopolítica mundial do petróleo.

Já, internamente, pode-se constatar que o Brasil precisará sanar suas dívidas históricas com a falta de infraestrutura adequada, com a falta de competitividade de suas empresas, e principalmente, com o atraso do seu sistema educacional, para desenvolver a potencialidade das reservas do pré-sal. A relação entre o Estado brasileiro e a Petrobras S. A. também precisará ser bem definida, equilibrando os interesses do Estado, a autonomia relativa de uma empresa nacional de capital aberto e o interesse dos investidores.

Por fim, mesmo que o impacto do pré-sal brasileiro não seja altamente significativo no mercado global, a ponto de transformar o Brasil em um grande exportador de petróleo, entendemos que, superados os desafios, sua realização responsável será suficiente para promover uma verdadeira autossuficiência energética, 
com potencial para sustentar o crescimento econômico interno, gerando uma oportunidade histórica para o desenvolvimento socioeconômico no território brasileiro.

\section{REFERÊNCIA BIBLIOGRÁFICA}

ABREU, S. F. de. O Recôncavo da Baia e o petróleo do Lobato: considerações de caráter geográfico, Revista Brasileira de Geografia (IBGE), Rio de Janeiro, v.1, n.2. 1986.

A Patagônia vista por um brasileiro. Revista Brasileira de Geografia (IBGE), Rio de Janeiro, v.2, n.4. 1940.

O solo da Amazônia. Revista Brasileira de Geografia (IBGE), Rio de Janeiro, v.4. n.2. 1942.

Águas de São Pedro. Revista Brasileira de Geografia (IBGE), Rio de Janeiro, v.6, n.4. 1944.

Aspectos geográficos, geológicos e políticos da questão do petróleo no Brasil.

Revista Brasileira de Geografia (IBGE), Rio de Janeiro, v.8, n.4. 1946.

AGÊNCIA NACIONAL DE PETRÓLEO, GÁS NATURAL E BIOCOMBUSTÍVEIS. Anuário estatístico brasileiro do petróleo, gás natural e biocombustíveis - 2012. Rio de Janeiro, 2012.

Anuário estatístico brasileiro do petróleo, gás natural e biocombustíveis - 2013. Rio de Janeiro, 2013.

AL-NAIMI, A. I. Saudi Arabiaoilandgasinvestimentoutlookandstrategies. In: Third OPEC Internacional seminar, Viena, 2006. Disponível em: <http://www.opec.org/opec_web/en/>. Acesso em: 11 dezembro 2012. 
BANDEIRA, L. A. M. Geopolítica e política exterior estados unidos, Brasil e América do Sul. Brasília: Fundação Alexandre de Gusmão, 2009.

A importância geopolítica da América do Sul na estratégia dos Estados Unidos.

Revista Espaço Acadêmico, ${ }^{\circ}$ 89. 2008.Disponível em: < http://www.espacoacademico.com.br/089/89bandeira.htm>. Acessado em: 14 Setembro 2013.

BARILLAS, J. L. M. Estudo do processo de drenagem gravitacional de óleo com injeção contínua de vapor em poços horizontais. 163f. Dissertação (Mestrado em Engenharia Química) - Departamento de Engenharia Química, Universidade Federal do Rio Grande do Norte, Natal. 2005.

BECKER, B. A geografia e o resgate da geopolítica. Revista Brasileira de Geografia, $\mathrm{n}^{\circ}$ 50 (1-2), p.99-125. 1988.

BENEVIDES, N. G.P.Relações Brasil-Estados Unidos no setor de energia. Brasília:Fundação Alexandre de Gusmão, 2011.

BRITISH PETROLEUM. StatisticalReviewof World Energy June 2012. Disponível em: <http://www.bp.com/assets/bp_internet/globalbp/globalbp_uk_english/reports_and_pub lications/statistical_energy_review_2011/STAGING/local_assets/pdf/statistical_review _of_world_energy_full_report_2012.pdf>. Acesso em: 10 fevereiro 2013.

BROS, A.; RICHARD Y. Relação energética Russia-União Européia. Mercator, Fortaleza, v.10, n. 21, p.7-31, 2011.

COSTAS, R. "Novo petróleo” promete mudar mapa geopolítico da energia. BBC Brasil - Economia. 02/05/2012. Disponível em: <http://www.bbc.co.uk/portuguese/noticias/2012/05/120501_petroleo_geopolitica_rc.sh tml>. Acesso em 14 setembro 2012. 
COSTA, W. M. da. Geografia política: discursos sobre o território e o poder. São Paulo: Edusp. 2008.

DROITSCH, D. NASA's James Hansen: tar sands is the "dirtiest of fuels" and "game over for the climate". Switchboard.Natural Resources Defense council Staff Blog. $11 / 05 / 2012$. Disponívelem: <http://switchboard.nrdc.org/blogs/ddroitsch/nasas_james_hansen_says_tar_sa.html>. Acessoem 15 fevereiro 2013.

FOOD\&WATERWATCH. Fracking: the new global water crisis. Califórnia, 2012. Disponível em: <http://www.foodandwaterwatch.org>. Acesso: 15 fevereiro 2013.

FORNETTI, V. EUA reduzem importação de petróleo do golfo Pérsico. Folha de São Paulo. 01/07/2012. Disponível em: <http://www1.folha.uol.com.br/mundo/1113407eua-reduzem-importacao-de-petroleo-do-golfo-persico.shtml>. Acesso em: 07 fevereiro 2013.

FOWLER, T. Produção de petróleo dos EUA alcança recorde histórico. The Wall Street Journal. 21/01/2013. Disponívelem: <http://online.wsj.com/article/SB10001424127887324624404578254250088783328.ht ml>. Acesso em: 02 fevereiro 2013.

GALL, N. Tecnologia e logística em águas profundas. O Estado de São Paulo, São Paulo, 27 fev. 2011. Caderno de Economia, p. B6

GERALDES, H. Obama rejeitou oleoduto gigante entre Canadá e EUA. Ciência P. 19/01/2012. Disponível em: <http://www.publico.pt/ciencia/noticia/obama-rejeitouconstrucao-de-oleoduto-gigante-entre-canada-e-eua--1529776>. Acesso em 11 fevereiro 2013. 
GLOBAL ENERGY COMPANY RANKINGS. Platts TOP250. Disponível em: <http://top250.platts.com/Top250Rankings/2012/Region/IntegratedOilandGas>. Acesso em: 13 fevereiro 2013.

HARVEY, D. O novo imperialismo. São Paulo: Edições Loyola, 2004. 187p.

HENRIQUES JR, M. F.; SZKLO, A.S.; SCHAEFFER, R. Processamento de petróleos não convencionais - perspectivas e desafios. IV PDPETRO, Campinas, São Paulo, 2007. Disponível em: <http://repositorio.int.gov.br:8080/repositorio/handle/123456789/117>. Acessoem 12 janeiro 2013.

HOYOS, C. The new seven sisters: oil and gas giants dwarf western rivals. FT.com, 2007. Disponível em: http://www.ft.com/intl/cms/s/2/471ae1b8-d001-11db- 94cb000b5df10621.html\#axzz1izEA6vKz. Acesso em: 04 de Janeiro de 2013.

INTERNATIONAL ENERGY AGENCY. Key World Energy Statistics 2012. Paris, 2012. Disponível em: <http://www.iea.org> . Acesso em 2 janeiro 2013.

JAFFE, A. M; SOLIGO, R. The internationaloilcompanies. James A. Baker III Institute for Public Policy of Rice University, 2007.Disponível em: <http://www.bakerinstitute.org/publications/NOC_IOCs_Jaffe-Soligo.pdf>. Acesso em: 18 dezembro 2012.

JUHASH, A. A tirania do petróleo: a mais poderosa indústria do mundo e o que pode ser feito para detê-la. São Paulo: Ediouro, 2009. 432p.

LACOSTE, Y. A geografia serve antes de mais nada para fazer a guerra. São Paulo: Papirus, 1977.

De laGéopolitiqueauxPaysages: dictionnaire de lá géographie. Paris: Armand Colini, 2003. 
MACHADO, M. S. Considerações sobre o Brasil e a Petrobras na integração sulamericana em tempos de globalização. In: PACHECO, S.M.M; MACHADO, M.S. (orgs). Globalização, Políticas Publicas e Reestruturação Territorial. Rio de Janeiro: 7 Letras, 2012. p. 158-184.

MACHADO, M. S.; REIS, C. M. A Petrobras na nova configuração energética global. Geo UERJ, Rio de Janeiro, v.2, p. 362-378, 2012. Disponível em: <http://www.epublicacoes.uerj.br/index.php/geouerj/article/view/2460>.

MAUGERI, L. Oil: the next revolution. The unprecedented upsurge of oil production capacity and what it means for the world.Cambridge: Harvard Kennedy School, 2012. $75 \mathrm{p}$.

MIYAMOTO, S. Os estudos geopolíticos no Brasil: uma contribuição para sua avaliação. Perspectivas, São Paulo, v.4, p.75-92. 1981.

MONIÉ, F.;BINSZTOK, J. (orgs.). Geografia e geopolítica do petróleo. Rio de Janeiro: Mauad X, 2012.

O’NEILL, J. BuildingBetter Global EconomicBRICs. GS Global Economics Website. Global economicspaper.n. 66. 16p. 2001. Disponível em: http://www.goldmansachs.com/our-thinking/topics/brics/brics-reports-pdfs/build-betterbrics.pdf. Acesso em: 05/02/2013.

ORGANIZAÇÃO NACIONAL DA INDÚSTRIA DO PETRÓLEO. As 15 maiores empresas de petróleo. Disponível em: <http://www.onip.org.br/noticias/sintese/as-15maiores-empresas-de-petroleo/>. Acessoem 8 fevereiro 2013.

\section{ORGANIZATION OF THE PETROLEUM EXPORTING COUNTRIES.Annual Statistical Bulletin 2014.Viena, 2014. Disponível em:}


http://www.opec.org/opec_web/static_files_project/media/downloads/publications/ASB 2014.pdf. Último acesso: 14set. 2014.

OPEC AnnualReport 2011. Viena, 2011. Disponível em: http://www.opec.org/opec_web/en/publications/337.htm. Último acesso: 28 jan 2013.

World Oil Outlook 2012. Viena, 2012. Disponível em: http://www.opec.org/opec_web/en/publications/340.htm. Último acesso: 28 jan 2013.

PARRAGA, M. Venezuela inicia produção de petróleo em dois projetos no Orinoco. UOL Notícias ECONOMIA. 27 setembro 2012. Disponível em: <http://economia.uol.com.br/ultimas-noticias/reuters/2012/09/27/venezuela-iniciaproducao-de-petroleo-em-dois-projetos-no-orinoco.jhtm>. Acesso em 02 fevereiro 2013.

PETROBRAS S.A. Plano de Negócios 2012-2016. Disponível em: $<$ http://www.investidorpetrobras.com.br/pt/plano-de-negocios/plano-de-negocios-20122016.htm>. Acesso em 10 fevereiro 2013.

PIMENTEL, F. O fim da era do petróleo e a mudança do paradigma energético mundial: perspectivas e desafios para a atuação diplomática brasileira. Brasília: Fundação Alexandre de Gusmão, 2011.

PIMENTEL, J. V. de S. O Brasil os BRICS e a agenda internacional. Brasília: FUNAG, 2012.

PIMENTEL, J. V. de S. (et. al.) A América do Sul e a integração regional Rio de Janeiro: Fundação Alexandre de Gusmão, 2012.

PINHO, C. A.Pré-sal: história, doutrina e comentário às leis. Belo Horizonte: Legal, 2010 . 
PIQUET, R. (Org.). Mar de riqueza, terras de contrastes. Rio de Janeiro, Ed. Mauad, 2011.

RAFAEL, J. M. C. Estratégia energética da Rússia. O caso do gás natural nas relações com a Europa. 146f. Dissertação (Mestrado em Estratégia) - Instituto Superior de Ciências Sociais e Políticas Universidade Técnica de Lisboa, Lisboa. 2012.

RAFFESTIN, C. Por uma geografia do poder. Ed Ática, 1980.

SANTOS, M. A natureza do espaço: técnica e tempo, razão e emoção. São Paulo: Hucitec, 1997.

- Metamorfoses do Espaço Habitado: fundamentos teóricos e metodológicos da geografia. São Paulo: Hucitec, 1988.

VALOR ECONÔMICO. Canadá testa maneiras pouco ortodoxas de extrair petróleo. 25/07/2012. Disponível em: <http://www.valor.com.br/empresas/2763628/canada-testamaneiras-pouco-ortodoxas-de-extrair-petroleo>. Acesso em 10 fevereiro 2013.

VELLOSO, J. P. dos R. (Coord). Brasil, novas oportunidades. Rio de Janeiro: José Olympio, 2010.

VENGOSH, A. Fracking findings. Duke Magazine. 2011. Disponível em:<http://dukemagazine.duke.edu/issues/070811/depqa.html>. Acesso em: 10 fevereiro 2013.

VESENTINI, J. W. As geopolíticas e a crise. In: novas geopolíticas, as representações do século XXI. São Paulo: Contexto. 2000.

YERGIN, D. O Petróleo: uma historia mundial de conquistas, poder e dinheiro. São Paulo: Paz e Terra, 2012. 1.080p.

\section{Sites Internet}

Geo UERJ. Rio de Janeiro - Ano 16, no. 25, v.2, $2^{\circ}$ semestre de 2014, pp.419-457

ISSN: 1415-7543 E-ISSN: 1981-9021

http://www.e-publicacoes.uerj.br/index.php/geouerj 
http://www.ultra.com.br/Ultra/Show.aspx?id_canal=owF/lppk5N0dSRncaecElQ== http://www.prominp.com.br/portal/prominp/pt br/prominp.htm

ANP (http://www.anp.gov.br),

CIPEG (Centro de Informações da Produção de Petróleo e Gás) do Departamento de Recursos Minerais do Estado do Rio de Janeiro

(http://www.petroleo.rj.gov.br/site/index.php),

Consultoria Legislativa (http://www2.camara.gov.br/a-camara/estruturaadm/conle).

Artigo recebido para publicação em agosto de 2014 .

Artigo aceito para publicação em outubro de 2014. 